\title{
Outbreak of methanol-induced optic neuropathy amid COVID-19 pandemic
}

\author{
Mohammad Reza Khalili $^{1}$ - Maryam Sadat Sadati ${ }^{2} \cdot$ Hamidreza Jahanbani-Ardakani $^{1}$
}

Received: 17 August 2020 /Revised: 24 August 2020 / Accepted: 27 August 2020 / Published online: 10 September 2020

(C) Springer-Verlag GmbH Germany, part of Springer Nature 2020

\section{Dear Editor,}

A pandemic related to a new coronavirus infection identified as COVID-19, as starting in Wuhan, China, was announced by the World Health Organization on March 11, 2020 [1]. As one of the hotspots, Iran experienced an unprecedented tremendous outbreak with over 340,000 cases of COVID-19 to date [2]. We recently witnessed a significant increase in the number of patients referring to our eye emergency department in Khalili Hospital affiliated to Shiraz University of Medical Sciences, Shiraz, Fars province, Iran, with methanol-induced optic neuropathy. The diagnosis was confirmed with a careful and detailed history taking and a comprehensive physical examination. All of the patients had history of alcohol drinking accompanied with painless, bilateral vision loss. Progressive loss of visual acuity usually had started with a blur at the fixation point. By taking a meticulous past drug history, we excluded other causes of toxic optic neuropathy including linezolid, ethambutol, amiodarone, and sildenafil. Other probable causes of optic neuropathy such as inflammatory and ischemic optic neuropathies were also excluded. In physical examination, optic nerve and macula were evaluated using slit lamp biomicroscope and a Volk 90 D condensing lens. Optic nerve hyperemia and swelling were assessed and recorded. Dyschromatopsia was assessed using Ishihara color vision plates.

From about 300 patients with methanol poisoning that were referred or consulted to us, 108 cases of methanolinduced optic neuropathy were diagnosed in our eye emergency department (unpublished data) in only 2 weeks' time. This

Mohammad Reza Khalili

khalilimr57@gmail.com

1 Poostchi Ophthalmology Research Center, Department of Ophthalmology, Shiraz University of Medical Sciences, Shiraz, Iran

2 Department of Dermatology, Molecular Dermatology Research Center, Shiraz University of Medical Sciences, Shiraz, Iran incidence is far higher than the total number of patients that have been referred to our center and were diagnosed as methanol-induced optic neuropathy within the last 15 years. The most common presenting symptom was blurred vision and most common sign was optic disc abnormality including hyperemia and swelling in optic nerve head.

Based on the information obtained from the patients, there were several factors that have led to the methanol poisoning and methanol-induced optic neuropathy outbreak.

Firstly, there is a misconception among the public that consuming alcohol-based drinks may be protective against COVID-19. Since Iran is an Islamic country, use of alcoholic drinks is prohibited and is against the country's law. Obtaining alcoholic drinks in Iran is quite difficult and those who wish to use alcoholic beverages have to buy them from illegal sources. Unfortunately, some illegal providers of alcohol to the alcohol abusers took advantage of this misconception and to increase their profit during the pandemic, sold methanol alcohol instead of ethanol. To deceive, they have mixed methanol with local everyday bleach in order to change the color of methanol to a white color so that it becomes indistinguishable from ethanol.

Secondly, with the emergence of the COVID-19 epidemic in Iran and its massive outbreak, people are buying hand sanitizers which are mostly ethanol based in an attempt to fight the spread of the virus. Alcohol-based hand sanitizers are available in most local markets since the Center for Disease Control and Prevention has recommended the use of hand sanitizers with more than $60 \%$ ethanol or $70 \%$ isopropanol for the hand hygiene. Some people have mistakenly bought industrial methanol-based solutions instead of ethanol.

Thirdly, during the quarantine period, free spare time led to increasing use of alcoholic drinks, [2, 3]. In addition, fear of death and unexpected unemployment with resultant anxiety and depression could be reasons for the surge in alcohol consumption [4]. All these together 
resulted in an outbreak in methanol-induced optic neuropathy amid COVID-19 pandemic with catastrophic consequences to patients' visual function that ultimately resulted in permanent visual impairment in many patients. We think that considering these issues is important for the public and policymakers as the consequences of such events might be as devastating as COVID-19 itself.

\section{Compliance with ethical standards}

Conflict of interest The authors declare that they have no conflict of interest.

\section{References}

1. Organization WH (2020) WHO Director-General's opening remarks at the media briefing on COVID-19-11 March 2020. Geneva

2. Chen C-Y, Wang I-A, Wang N, Lu M-C, Liu C-Y, Chen WJ (2019) Leisure activity participation in relation to alcohol purchasing and consumption in adolescence. Addict Behav 90:294-300

3. Finlay AK, Ram N, Maggs JL, Caldwell LL (2012) Leisure activities, the social weekend, and alcohol use: evidence from a daily study of first-year college students. J Stud Alcohol Drugs 73(2):250-259

4. Johannessen EL, Andersson HW, Bjørngaard JH, Pape K (2017) Anxiety and depression symptoms and alcohol use among adolescents-a cross sectional study of Norwegian secondary school students. BMC Public Health 17(1):494

Publisher's note Springer Nature remains neutral with regard to jurisdictional claims in published maps and institutional affiliations. 